\title{
Updates on Pharmacological Treatment of Post-Traumatic Stress Disorder
}

\author{
Rishav Koirala, ${ }^{1,2}$ Erik Ganesh lyer Søegaard, 1,3 Suraj Bahadur Thapa ${ }^{1,3}$ \\ 'Institute of Clinical Medicine, Faculty of Medicine, University of Oslo, ${ }^{2}$ Psycho-oncology Clinic, Nepal Cancer Hospital and \\ Research Center, Harisiddhi, Lalitpur, Nepal, ${ }^{3}$ Division of Mental Health and Addiction, Oslo University Hospital, Oslo.
}

Post-Traumatic Stress Disorder affects a significant proportion of those who have been exposed to exceptionally threatening or catastrophic events or situations such as earthquakes, rape and civil war. The condition can often become chronic and disabling. Medical intervention can therefore be of paramount importance. There are no national guidelines for trauma disorders in Nepal and there is a lack of adequate knowledge regarding drug treatment of PTSD among doctors and other service providers. Though psychotherapy is internationally regarded as the first line treatment for PTSD, it is often not feasible in Nepal due to lack of resources and skilled health workers in this field. The use of right psycho-pharmacotherapy is therefore important to reduce the burden of disease. A wide range of pharmacotherapy has been tested in the treatment of PTSD. This article is based on a selected sample of relevant articles from PubMed, PsycINFO, national guidelines from other countries and our own clinical experience. We have tried to give a concise and practical review regarding the use of drugs, their side effects and available evidence in the treatment of PTSD. The main findings point to use of Selective Serotonin Reuptake Inhibitors as the first line pharmacotherapy, and they can have effect on the full range of symptoms in PTSD. SNRIs show similar efficacy. Adjuvant drugs like Alpha-blockers and atypical antipsychotics have shown strong evidence in treating partially remitted cases and resolving ancillary symptoms.

Keywords: Antidepressive Agents; Drug Therapy; Post-Traumatic; Psychotropic Drugs; Stress Disorder

\section{INTRODUCTION}

Posttraumatic stress disorder (PTSD) is a common mental disorder among people who have been exposed to direct or indirect severe traumatic experiences such as war, rape, earthquakes etc. ${ }^{1}$ The negative effects of PTSD can often be lengthy because it causes reduction of overall function and many of those having PTSD are reluctant to seek treatment.

Nepalese people have been repeatedly exposed to significant trauma, from a decade long Maoist War to a mega-earthquake on 2015. In a study done in Nepal, on the internally displaced persons, a high prevalence of PTSD was seen among them. ${ }^{2}$ Hence, addressing the impact of this trauma is important, to help the general population to return to a normal life and handle further stressors in life.

This article gives basic idea about symptoms of PTSD along with the latest updates on treatment in context to the available drugs in Nepal and practical tips on treatment.

\section{LITERAURE SEARCH AND REVIEW}

There are several trauma related mental health

Correspondence: Dr. Rishav Koirala, Institute of Clinical Medicine, Faculty of Medicine, University of Oslo, Oslo, Norway. Email: rishark@gmail.com. Phone no: +977-9851111515. 
conditions in addition to PTSD. Acute stress reaction, Personality change after catastrophic experience (ICD10) and Complex PTSD (proposed to be included in ICD-11), to name a few. But in this unsystematic review, however, we have looked only at studies related to PTSD and Pharmacotherapy from the last 10 years. This article is based on a selected sample of relevant articles from PubMed, PsycINFO, national guidelines from other countries and our own clinical experience. Psychotherapy has remained the first line treatment preferred for PTSD for a long time..$^{3-5}$ This could be one of the reasons why pharmacotherapy has been undermined and not focused on. Nepal has limited resources, especially lacking are trauma focused trained psychologists. Medicines, however, are more abundant and can be readily available even in rural areas. Effective use of pharmacotherapy can therefore act as a significant boon to the entire traumaaffected community. In this review we have focused on the drugs that are available in Nepal, especially those drugs, which are familiar to practicing professionals, like psychiatrists, general practitioners, MBBS doctors and internists.

\section{SYMPTOM PROFILE OF PTSD}

According to International Classification of Diseases-10 (ICD-10) PTSD symptoms can be divided into three clusters of symptoms. The first being persistent remembering or "reliving" the stressor by intrusive flash backs, vivid memories, recurring dreams, or by experiencing distress when exposed to circumstances resembling or associated with the stressor. The second being avoidance symptoms, i.e. actual or preferred avoidance of circumstances resembling or associated with the stressor (not present before exposure to the stressor). And the last cluster being hyperarousal symptoms, which is persistent symptoms of increased psychological sensitivity and arousal (not present before exposure to the stressor) like disturbance in falling or staying asleep, irritability or outbursts of anger, difficulty in concentration, hyper-vigilance and exaggerated startle response. ${ }^{6}$ Diagnostic and Statistical Manual of Mental Disorders(DSM 5) has, in addition, the fourth cluster concerning an adverse change in cognition and state of the mood. ${ }^{7}$ PTSD can only be diagnosed after these symptoms are present at least for four weeks. And while treating PTSD patients, sleep disorders should always be addressed as chronic insomnia and recurrent nightmares are among the most distressing symptoms of PTSD, and evidence suggests that they are the core feature of the disorder. ${ }^{8-10}$ PTSD is the only mental illness that has a clear known necessary psychological cause; severe psychological trauma. We now know that acute trauma triggers a number of biological changes in the body. In both nervous and endocrine systems, it can cause a cascade of complex reactions. For example, trauma can cause dysregulation of HPA axis and neuroendocrine system. Some of these changes persist when the condition develops to PTSD. Stress-related hormones like cortisol, norepinephrine, epinephrine, vasopressin, oxytocin, glutamate, dopamine, endogenous opiates and others are altered in PTSD. ${ }^{11-13}$ The serotonergic and adrenergic nervous systems are also affected by trauma. ${ }^{14}$ Furthermore, a number of neuroanatomic abnormalities have been found in people with PTSD. From a biomedical perspective it is logical to assume that this disorder may be treated with medications that can regulate some of these biological changes. Still, the biological changes are complex and not fully known, and currently there are no medications primarily targeting only PTSD.

\section{SYMPTOM FOCUS}

Although medicines have not been developed specifically for this disease, there are several medicines, which have shown to help many of the PTSD symptoms. For example; sleep problems, nightmares, anxiety and depressive symptoms, intense inner turmoil and agitation can be treated by medicines with or without concomitant psychotherapy. Furthermore, posttraumatic stress disorder shows high comorbidity with many other mental disorders. ${ }^{15}$ Adjustment disorder, major depression, anxiety disorders, substance use disorders and in some cases psychotic disorders are often seen together with PTSD. Various psychopharmacological drugs have a documented positive effect on, and are usually an important part of the treatment in such cases. But it should always be remembered that in "the $1^{\text {st }}$ month after trauma three Ps should be followed: Don't Pathologize "this is a normal response to an abnormal situation", Don't Psychologize (don't facilitate emotional reaction via group therapy, or stressful debriefing), and Don't Pharmacologize (there is no evidence that prophylactic medication treatment may prevent the development of PTSD)". ${ }^{5}$

\section{PSYCHOTHERAPY}

Despite enhanced focus on biological changes in PTSD, specific pathognomonic indicator or biomarkers of PTSD have not been found. The main treatment for PTSD is primarily psychotherapy and there are different forms of effective psychotherapy in PTSD such as Trauma focused psychotherapy and Eye movement desensitization and reprocessing (EMDR). ${ }^{4}$ Psychotherapy alone, however, does not lead to satisfactory improvement in a substantial proportion of patients with PTSD. There are also some cases 
where trauma-focused therapy may be unsuccessful or unwanted by the patient. Both research and our clinical experience show that drug therapy alone or adjunct to psychotherapy often is warranted and needed. ${ }^{16}$

\section{SELECTIVE SEROTONIN REUPTAKE INHIBITORS (SSRIS)}

SSRIs have shown efficacy in symptomatic relief and in preventing relapse. This is considered to be the first-line drug treatment for PTSD. ${ }^{17}$ Presumably, there is little difference between the various SSRIs, but Fluoxetine and Paroxetine have the best-documented effect on PTSD symptoms. ${ }^{18}$ Along with those two we should also list Sertraline in the first line list as it also has shown efficacy equivalent to Fluoxetine..$^{19,20}$ If tolerated, we advise trying a higher dose than the standard dose used for treatment of the depressive disorder. It has, however, been found to be less effective in men than women, and even less effective in those with torture, war and/or complex trauma. Dosing: SSRIs are started with a lower dose $120 \mathrm{mg}$ OD for Paroxetine, $20 \mathrm{mg}$ OD for Fluoxetine and $25 \mathrm{mg}$ OD for Sertraline) and gradually build up to the upper end of the tolerated high dose (i.e. increasing Paroxetine 10 mg every 2 weeks up to $60 \mathrm{mg}$ until the required effect is achieved. Dose can be increased in Fluoxetine in the same dosing pattern. Sertraline should be increased to $50 \mathrm{mg}$ after a week, then wait at least 4 weeks before increasing the dose. A maximum of $200 \mathrm{mg}$ can be reached, increasing 50 mg every week). ${ }^{21}$

Common side effects such as sexual dysfunction, gastrointestinal (decreased appetite, nausea, diarrhea, constipation, dry mouth), insomnia, agitation, tremors, headache, dizziness, and sedation should be looked for. Fluoxetine and Sertraline are given in the morning, after meal so as to avoid gastrointestinal disturbances and insomnia. Whereas, Paroxetine is usually given at night, before bedtime as it usually causes sedation.

\section{SEROTONIN-NOREPINEPHRINE INHIBITORS (SNRIS)}

\section{REUPTAKE}

SNRIs, especially venlafaxine is another drug that has shown similar efficacy compared to SSRIs. Although there are few studies comparing SNRIs to SSRIs, a meta-analysis found that Venlafaxine is as effective as SSRIs. ${ }^{18}$ Randomized controlled trials have shown that Venlafaxine depot tablets are more effective than placebo in reducing PTSD symptoms. ${ }^{22}$ Venlafaxine, however, has shown to have little or no effect on nightmares and sleep difficulties, and can increase these problems in some cases. ${ }^{23}$
Dosing: Venlafaxine extended release should be started at the dose of $37.5 \mathrm{mg}$ and increased to $75 \mathrm{mg}$ in a week. Then gradual increments of the dose by $37.5 \mathrm{mg}$ should be done every 4 weeks until the required effect is achieved or highest tolerated dose is reached. The maximum dose is $375 \mathrm{mg}{ }^{21}$

Common side effects encountered are headache, nervousness, insomnia, sedation, sexual dysfunction, nausea. During stopping the drug the dose should be tapered very slowly to avoid Discontinuation syndrome. ${ }^{21}$

\section{OTHER ANTIDEPRESSANTS}

Though there is no strong evidence in support of the use of Tricyclic antidepressants (TCAs) in PTSD, it has been used in PTSD for many years and is still used especially where insomnia and pain are prominent problems and especially among torture victims where often few other therapies are effective. ${ }^{24}$ Amitriptyline has been most used and Desimipramine had shown better efficacy than SSRIs in PTSD, especially where there are comorbid alcohol problems. ${ }^{25}$ These medicines should still have a place in the treatment of PTSD and we hope to see more studies on new opportunities for older medications.

\section{ALPHA AND BETA-BLOCKERS}

Use of these agents in PTSD is aimed at intrusion- and hyperactivity symptoms. They are mainly used as an adjunct agent to the main treatment of PTSD. These hyper-arousal symptoms are considered to be due to hyperactivity in sympathetic nervous system mediated through the adrenergic- and noradrenergic systems. Blockade of alpha-1 receptors using Prazosin can reduce many PTSD symptoms. ${ }^{26,27}$ A review article concluded that Prazosin is effective against insomnia and nightmares in PTSD. ${ }^{23}$

Propranolol is a beta blocker that has effects on acute adrenergic PTSD symptoms. ${ }^{28}$ Carvedilol, a combined alpha- and beta-blocker, has also been used by clinicians in PTSD patients with some success. However, some recent research has not supported the efficacy of the beta-blockers, especially Propranolol in PTSD. ${ }^{29}$ When used, it is important to monitor heart rate and blood pressure as these medications can cause lower blood pressure.

Dosing: Prazosin should be started with $1 \mathrm{mg}$ in the evening and gradually increased to $3-10 \mathrm{mg}$ until the symptoms improve or the side effects are not tolerated. 
Common side effects of Prazosin are dizziness, lightheadedness, nausea, sedation and headache.

\section{ALPHA 2 AGONIST / ANTAGONIST}

Clonidine is an alpha- 2 agonist that has been shown to have effects against nightmares and hyper-arousal. ${ }^{30}$ Clinicians have somewhat mixed experiences with this preparation. Mirtazapine blocks the alpha-2 auto-receptor and has also shown efficacy in PTSD, particularly insomnia in the relatively scarce research that exists. ${ }^{31,32}$ Overall, there is a need for further research on these medicines to say that they have lasting and profound efficacy in the treatment of PTSD and related symptoms.

Dosing: Start Clonidine $25 \mu \mathrm{g}$ twice daily and gradually increase $50 \mu \mathrm{g}$ every week until the required effect is achieved or up to highest tolerable dose. The maximum dose is $150 \mu \mathrm{g}$, total in a day.

Common side effects that might be encountered are sedation, hypotension, dizziness and dry mouth.

For Mirtazapine can be started with $7.5 \mathrm{mg}$ per day, before sleep and increased to $15 \mathrm{mg}$ in a week. Then increase $15 \mathrm{mg}$ every 2 week until the desired effect is achieved or the highest tolerable dose is reached. The maximum dose per day is $45 \mathrm{mg}$.

Common side effects that might be encountered are sedation, weight gain, dry mouth and constipation.

\section{ANTIPSYCHOTICS}

First-generation antipsychotics have been used in anxious patients with PTSD but are prescribed less recently due to the side effect burden and the introduction of newer anti-psychotics. In recent years, there has been a growing use of second-generation antipsychotics in trauma disorders. A meta-analysis has concluded that such atypical antipsychotics had an effect on intrusive symptoms but not against the avoidance or hyperarousal symptoms. ${ }^{33}$ Antipsychotics may also be useful in trauma-related hallucinations or other intense intrusive symptoms. A metaanalysis done by Liu XH in 2014 has found that atypical antipsychotics are superior to placebo especially when dealing with intrusive symptoms and hyperarousal. ${ }^{34}$ Furthermore, they can also be used as an adjunct medication to SSRI or SNRIs. Second-generation antipsychotics such as Risperidone, Olanzapine and Quetiapine in lower doses are often used. Olanzapine has been shown to be effective as monotherapy by Paul Carey and his team. ${ }^{35}$ Similarly, a research done by Padala and team has shown that Risperidone has shown efficacy as a monotherapy for PTSD. ${ }^{36}$ Quetiapine has also shown evidence as a monotherapy too for PTSD. ${ }^{37}$ UpToDate has recommended Quetiapine as the monotherapy based on the absence of other medications proven to be effective and with their clinical experience that some patients appear to benefit from these agents. ${ }^{38}$

Dose: Start Risperidone at a dose of $1 \mathrm{mg}$. If the adequate response is not seen, increase the dose by $1 \mathrm{mg}$ weekly up to $4 \mathrm{mg}$ or until the side effects are not tolerated. If there is no significant clinical benefit seen even after 2 weeks of the use of maximum tolerated dose gradually taper and discontinue the medicine as it was increased.

The common side effects associated with Risperidone are dizziness, sedation, hypotension, dose dependent extrapyramidal syndrome etc. These medicines are usually taken in the night time so as to avoid the side effect of sedation. ${ }^{21}$

\section{MOOD STABILIZERS}

Several types of mood stabilizers have been investigated in the treatment of PTSD but they lack good documentation regarding effect. Gabapentin, Lamotrigine and Topiramate have some effect in some studies and can be tried in cases where other medication is not tolerated. ${ }^{39,40}$ Valproic Acid (VPA is one of the emerging drug that has started to be extensively studied as monotherapy as well as a supplement for Psychotherapies. ${ }^{41}$ The recent discovery that VPA acts as a histone deacetylase (HDAC) inhibitor has led to the expectation that it will be used as an adjunctive agent with existing psychotherapies for PTSD. ${ }^{42}$

\section{BENZODIAZEPINES}

Benzodiazepines have previously been used extensively to treat anxiety and hyperarousal symptoms of PTSD but these should be avoided since this group of patients seems to be especially vulnerable to tolerance and addiction. ${ }^{43,44}$ If one still decides to use them in an acute crisis setting, they should be used for as short period as possible. We advise to avoid alprazolam among the benzodiazepines as it has the highest chance of dependency. Moreover, these preparations lack lasting efficacy against PTSD according to our experience.

\section{OTHER MEDICATIONS}

There are several medications on the experimental stages that have shown some efficacy but they are still far from being used in our clinical practice. NMDA 
receptors have shown to be involved in fear extinction and activation of NMDA receptor can enhance fear extinction, hence can help in treating PTSD symptoms. ${ }^{45}$ D-cycloserine, an NMDA (N-methyl-D-aspartic acid) partial agonist was shown to augment the effects of fear extinction/exposure therapy in both humans and animals. ${ }^{46}$

Intranasal cortisone has shown some efficacy especially in women. ${ }^{47,48}$ Hydrocortisone during acute trauma was found to have a possible protective effect against PTSD in a meta-analysis. ${ }^{49} \mathrm{An} \mathrm{RCT}$ has also shown efficacy of intranasal oxytocin as an adjuvant to psychotherapy because of its anxiolytic and pro-social properties. ${ }^{47}$

In another RCT study, effect of intravenous Ketamine for patients with chronic PTSD has been reported. ${ }^{50}$ Dynorphin/KOR system, a part of endogenous opioids is involved in the regulation of dysphoric components of stress, particularly after exposure to chronic stress. ${ }^{51}$ Opiates also have been tried and Morphine has been linked with certain preventive effects in some smaller studies. $^{52}$

Similarly, new studies have linked PTSD with the disruptions in cannabinoid system. ${ }^{53,54}$ Hence, novel drugs such as nabilone, which is a Cannabinoid $1\left(\mathrm{CB}_{1}\right)$ agonist have been used to treat PTSD symptoms with success. ${ }^{55}$ But all of these drugs are in experimental phase, though they give hope for better pharmacological treatment for PTSD.

\section{SUIMIMARY}

PTSD is a psychiatric disorder with complex neurobiological changes that should be treated with psychotherapy as first choice where available and requested. Drug therapy may be applicable both as a supplement to psychotherapy or alone. In Nepal access to professionals skilled in psychotherapy is largely lacking. Therefore, pharmacotherapy can play an especially important role in treatment of the disorder through decreasing of the symptom burden in the sufferers. We recommend using SSRIs as the $1^{\text {st }}$ line drug. In Nepal, Fluoxetine and Sertraline would be the best choice due to availability in remote parts of country, cost (Paroxetine costs around 3 times more than Fluoxetine) and less interaction. These factors are the main reasons for discontinuation of medicine, once started. Fluoxetine is also added to the free drugs list provide by the government, hence increasing the accessibility to the drug. Use of second generation antipsychotics, though emerging as a monotherapy, we recommend to use it as a second line or an adjuvant as the side effects are significantly more than the SSRIs. If symptoms persist even after increasing the dose to the maximum tolerated, alpha-blockers (e.g. Prazosin) or a second-generation antipsychotics (e.g. Risperidone, Quetiapine) can be added according to the associated need or ancillary symptoms. Accessibility of Risperidone will be increased as this too is added to the free drug list of the government. Other Betablockers, alpha-agonists, neuroleptics and antiepileptics can be effective as adjunctive medicine for specific symptoms or for relevant psychiatric comorbidity but have significantly less evidence to support it. It is highly advisable to avoid benzodiazepines in the treatment of PTSD and other trauma-related disorders.

Conflict of Interest: None.

\section{REFERENCES}

1. World Health Organization. The ICD-10 classification of mental and behavioural disorders : clinical descriptions and diagnostic guidelines. Geneva: World Health Organization; 1992. 362 p. [Full text]

2. Thapa SB, Hauff E. Psychological distress among displaced persons during an armed conflict in Nepal. Soc Psychiatry Psychiatr Epidemiol. 2005;40(8):672-9. [PubMed | DOI ]

3. Ursano RJ, Bell C, Eth S, Friedman M, Norwood A, Pfefferbaum B, et al. Practice guideline for the treatment of patients with acute stress disorder and posttraumatic stress disorder. Am J Psychiatry. 2004;161(11 Suppl):3-31. [PubMed ]

4. Post-traumatic stress disorder: management [Internet]. NICE. 2014. [Full text]

5. Bandelow B, Sher L, Bunevicius R, Hollander E, Kasper S, Zohar J, et al. Guidelines for the pharmacological treatment of anxiety disorders, obsessive-compulsive disorder and posttraumatic stress disorder in primary care. Int J Psychiatry Clin Pract. 2012;16(2):77-84. [PubMed | DOI]

6. World Health Organization. The ICD-10 classification of mental and behavioural disorders : diagnostic criteria for research. Geneva: World Health Organization; 1993. xiii, 248 p.p. [Full Text]

7. American Psychiatric Association., American Psychiatric Association. DSM-5 Task Force. Diagnostic and statistical manual of mental disorders : DSM-5. 5th ed. Washington, D.C.: American Psychiatric Association; 2013. 947 p. [DOI] 
8. Brownlow JA, Harb GC, Ross RJ. Treatment of Sleep Disturbances in Post-Traumatic Stress Disorder: A Review of the Literature. Curr Psychiatry Rep. 2015;17(6):41. [PubMed | DOI]

9. Spoormaker VI, Montgomery P. Disturbed sleep in post-traumatic stress disorder: secondary symptom or core feature? Sleep Med Rev. 2008;12(3):169-84. [PubMed | DOI ]

10. Germain A. Sleep disturbances as the hallmark of PTSD: where are we now? Am J Psychiatry. 2013;170(4):372-82. [PubMed | DOI]

11. Yehuda R, Flory JD, Southwick S, Charney DS. Developing an agenda for translational studies of resilience and vulnerability following trauma exposure. Ann N Y Acad Sci. 2006;1071:379-96. [PubMed | DOI]

12. Olff M, Guzelcan Y, de Vries GJ, Assies J, Gersons BP. HPAand HPT-axis alterations in chronic posttraumatic stress disorder. Psychoneuroendocrinology. 2006;31(10):1220-30. [PubMed | DOI]

13. Passos IC, Vasconcelos-Moreno MP, Costa LG, Kunz $\mathrm{M}$, Brietzke E, Quevedo J, et al. Inflammatory markers in post-traumatic stress disorder: a systematic review, meta-analysis, and meta-regression. Lancet Psychiatry. 2015;2(11):1002-12. [PubMed | DOI]

14. Kilpatrick DG, Koenen KC, Ruggiero KJ, Acierno R, Galea $\mathrm{S}$, Resnick HS, et al. The serotonin transporter genotype and social support and moderation of posttraumatic stress disorder and depression in hurricane-exposed adults. Am J Psychiatry. 2007;164(11):1693-9. [PubMed | DOI]

15. Kessler RC, Sonnega A, Bromet E, Hughes M, Nelson CB. Posttraumatic stress disorder in the National Comorbidity Survey. Arch Gen Psychiatry. 1995;52(12):1048-60. [PubMed]

16. Pratchett LC, Daly K, Bierer LM, Yehuda R. New approaches to combining pharmacotherapy and psychotherapy for posttraumatic stress disorder. Expert Opin Pharmacother. 2011;12(15):2339-54. [PubMed | DOI

17. Stein DJ, Ipser JC, Seedat S. Pharmacotherapy for post traumatic stress disorder (PTSD). Cochrane Database Syst Rev. 2006 Jan 25;(1):CD002795. [PubMed | DOI | Full Text]

18. Hoskins M, Pearce J, Bethell A, Dankova L, Barbui C, Tol WA, et al. Pharmacotherapy for post-traumatic stress disorder: systematic review and meta-analysis. $\mathrm{Br} \mathrm{J}$ Psychiatry. 2015;206(2):93-100. [PubMed | DOI]

19. Ipser JC, Stein DJ. Evidence-based pharmacotherapy of post-traumatic stress disorder (PTSD). Int J Neuropsychopharmacol. 2012;15(6):825-40. [PubMed DOI ]

20. Watts BV, Schnurr PP, Mayo L, Young-Xu Y, Weeks WB, Friedman MJ. Meta-analysis of the efficacy of treatments for posttraumatic stress disorder. J Clin Psychiatry. 2013;74(6):e541-50. [PubMed | DOI]

21. Stahl SM. Stahl's essential psychopharmacology : prescriber's guide. Fifth edition. ed. New York, NY: Cambridge University Press; 2014. 802 P.
22. Davidson J, Rothbaum BO, Tucker P, Asnis G, Benattia I, Musgnung JJ. Venlafaxine extended release in posttraumatic stress disorder: a sertraline- and placebo-controlled study. J Clin Psychopharmacol. 2006;26(3):259-67. [PubMed | DOI]

23. Lipinska G, Baldwin DS, Thomas KG. Pharmacology for sleep disturbance in PTSD. Hum Psychopharmacol. 2016;31(2):156-63. [PubMed | DOI ]

24. Puetz TW, Youngstedt SD, Herring MP. Effects of Pharmacotherapy on Combat-Related PTSD, Anxiety, and Depression: A Systematic Review and Meta-Regression Analysis. PLoS One. 2015;10(5):e0126529. [PubMed | DOI]

25. Davidson J. Vintage treatments for PTSD: a reconsideration of tricyclic drugs. J Psychopharmacol. 2015;29(3):264-9. [PubMed | DOI

26. Singh B, Hughes AJ, Mehta G, Erwin PJ, Parsaik AK. Efficacy of Prazosin in Posttraumatic Stress Disorder: A Systematic Review and Meta-Analysis. Prim Care Companion CNS Disord. 2016;18(4). [PubMed | DOI]

27. Khachatryan D, Groll D, Booij L, Sepehry AA, Schutz CG. Prazosin for treating sleep disturbances in adults with posttraumatic stress disorder: a systematic review and meta-analysis of randomized controlled trials. Gen Hosp Psychiatry. 2016;39:46-52. [PubMed | DOI ]

28. Giustino TF, Fitzgerald PJ, Maren S. Revisiting propranolol and PTSD: Memory erasure or extinction enhancement? Neurobiol Learn Mem. 2016;130:26-33. [PubMed | DOI ]

29. Steenen SA, van Wijk AJ, van der Heijden GJ, van Westrhenen $\mathrm{R}$, de Lange J, de Jongh A. Propranolol for the treatment of anxiety disorders: Systematic review and meta-analysis. J Psychopharmacol. 2016;30(2):128-39. [PubMed | DOI ]

30. Alao A, Selvarajah J, Razi S. The use of clonidine in the treatment of nightmares among patients with co-morbid PTSD and traumatic brain injury. Int J Psychiatry Med. 2012;44(2):165-9. [PubMed | DOI]

31. Jeffreys M, Capehart B, Friedman MJ. Pharmacotherapy for posttraumatic stress disorder: review with clinical applications. J Rehabil Res Dev. 2012;49(5):703-15. [PubMed]

32. Alderman CP, McCarthy LC, Marwood AC. Pharmacotherapy for post-traumatic stress disorder. Expert Rev Clin Pharmacol. 2009;2(1):77-86. [PubMed | DOI

33. Han C, Pae CU, Wang SM, Lee SJ, Patkar AA, Masand PS, et al. The potential role of atypical antipsychotics for the treatment of posttraumatic stress disorder. J Psychiatr Res. 2014;56:72-81. [PubMed | DOI ]

34. Liu XH, Xie XH, Wang KY, Cui H. Efficacy and acceptability of atypical antipsychotics for the treatment of post-traumatic stress disorder: a meta-analysis of randomized, double-blind, placebo-controlled clinical trials. Psychiatry Res. 2014;219(3):543-9. [PubMed | DOI ]

35. Carey P, Suliman S, Ganesan K, Seedat S, Stein DJ. Olanzapine monotherapy in posttraumatic stress disorder: efficacy in a randomized, double-blind, placebo-controlled study. Hum Psychopharmacol. 2012;27(4):386-91. [PubMed | DOI 
36. Padala PR, Madison J, Monnahan M, Marcil W, Price P, Ramaswamy S, et al. Risperidone monotherapy for post-traumatic stress disorder related to sexual assault and domestic abuse in women. Int Clin Psychopharmacol. 2006;21(5):275-80. [PubMed]

37. Villarreal G, Hamner MB, Canive JM, Robert S, Calais LA, Durklaski V, et al. Efficacy of Quetiapine Monotherapy in Posttraumatic Stress Disorder: A Randomized, Placebo-Controlled Trial. Am J Psychiatry. 2016;173(12):1205-12. [PubMed | DOI]

38. Murray B Stein M, MPH. Pharmacotherapy for posttraumatic stress disorder in adults. In: Richard Hermann M, editor. UpToDate. Waltham, MA. (Accessed on March 26, 2013.): UpToDate; 2017.

39. Berlant JL. Topiramate in posttraumatic stress disorder: preliminary clinical observations. J Clin Psychiatry. 2001;62 Suppl 17:60-3 [PubMed]

40. Kishimoto A, Goto Y, Hashimoto K. Post-traumatic Stress Disorder Symptoms in a Female Patient Following Repeated Teasing: Treatment with Gabapentin and Lamotrigine and the Possible Role of Sensitization. Clin Psychopharmacol Neurosci. 2014;12(3):240-2. [PubMed | DOI]

41. Adamou M, Puchalska S, Plummer W, Hale AS. Valproate in the treatment of PTSD: systematic review and meta analysis. Curr Med Res Opin. 2007;23(6):1285-91; [PubMed | DOI ]

42. Martin C. Comprehensive guide to post-traumatic stress disorders. New York, NY: Springer Berlin Heidelberg; 2016. pages $\mathrm{cm} \mathrm{p}$.

43. Mohamed S, Rosenheck RA. Pharmacotherapy of PTSD in the U.S. Department of Veterans Affairs: diagnosticand symptom-guided drug selection. J Clin Psychiatry. 2008;69(6):959-65 [PubMed]

44. Harpaz-Rotem I, Rosenheck RA, Mohamed S, Desai RA. Pharmacologic treatment of posttraumatic stress disorder among privately insured Americans. Psychiatr Serv. 2008;59(10):1184-90. [PubMed]

45. Myers KM, Carlezon WA, Jr., Davis M. Glutamate receptors in extinction and extinction-based therapies for psychiatric illness. Neuropsy chopharmacology. 2011;36(1):274-93. [PubMed | DOI ]
46. Norberg MM, Krystal JH, Tolin DF. A meta-analysis of D-cycloserine and the facilitation of fear extinction and exposure therapy. Biol Psychiatry. 2008;63(12):1118-26. [PubMed | DOI ]

47. Koch SB, van Zuiden M, Nawijn L, Frijling JL, Veltman DJ, Olff M. Intranasal Oxytocin Normalizes Amygdala Functional Connectivity in Posttraumatic Stress Disorder. Neuropsychopharmacology. 2016;41(8):2041-51. [PubMed | DOI ]

48. Palgi S, Klein E, Shamay-Tsoory SG. Oxytocin improves compassion toward women among patients with PTSD. Psychoneuroendocrinology. 2016;64:143-9. [PubMed | DOI ]

49. Amos T, Stein DJ, Ipser JC. Pharmacological interventions for preventing post-traumatic stress disorder (PTSD). Cochrane Database Syst Rev. 2014;7:CD006239; [PubMed | DOI | Full Text ]

50. Feder A, Parides MK, Murrough JW, Perez AM, Morgan JE, Saxena S, et al. Efficacy of intravenous ketamine for treatment of chronic posttraumatic stress disorder: a randomized clinical trial. JAMA Psychiatry. 2014;71(6):681-8. [PubMed | DOI ]

51. Waller RJ. Fostering child \& adolescent mental health in the classroom. Thousand Oaks: Sage Publications; 2006. xi, 339 p.p.

52. Ragen BJ, Seidel J, Chollak C, Pietrzak RH, Neumeister A. Investigational drugs under development for the treatment of PTSD. Expert Opin Investig Drugs. 2015;24(5):659-72/ [PubMed | DOI ]

53. Hill MN, Bierer LM, Makotkine I, Golier JA, Galea S, McEwen BS, et al. Reductions in circulating endocannabinoid levels in individuals with post-traumatic stress disorder following exposure to the World Trade Center attacks. Psychoneuroendocrinology. 2013;38(12):2952-61. [PubMed | DOI]

54. Neumeister A, Normandin MD, Pietrzak RH, Piomelli D, Zheng MQ, Gujarro-Anton A, et al. Elevated brain cannabinoid CB1 receptor availability in post-traumatic stress disorder: a positron emission tomography study. Mol Psychiatry. 2013;18(9):1034-40. [PubMed | DOI]

55. Fraser GA. The use of a synthetic cannabinoid in the management of treatment-resistant nightmares in posttraumatic stress disorder (PTSD). CNS Neurosci Ther. 2009;15(1):84-8. [PubMed | DOI] 